\title{
Zaman etüdü ve ahşap kent mobilyasında bir uygulama örneği
}

\author{
Halil Erdem Yücel ${ }^{1}$ (D), Tuncer Dilik²*
}

\section{$\ddot{O} \mathbf{z}$}

$\mathrm{Bu}$ makalede, zaman etüdü ile ilgili olarak mobilya endüstrisinde yeterli bir uygulamanın olmadığı ve bilimsel çalışmaların bulunmadığı gerçeğinden hareketle, ahşap kent mobilyası üretimi örneği üzerinden bir zaman etüdü uygulaması incelenmiştir. Araştırma çerçevesinde, 10'ar adet ön etüt çalı̧̧ması yapılmıştır. Bu kapsamda yapılan ön etüd sonucu, üç makine ve bir aşamada 10'ar adet zaman ölçümü yapılmıştır. Standart sapmalar, \%95 güvenle $\% 5$ hata payı ile hesaplanmıştır. Bu çalışmadaki zaman etüdü, ahşap kent mobilyaları üreten bir işletmedeki piknik masasının ve bankın montaj aşamasındaki standart zamanının tespitine yönelik uygulanmıştır. Bu kapsamda, elde edilen temel zaman verileri üzerinden değerlendirme yapıldığında bir adet piknik masasının montajı için standart zamanın 11.58 dakika, bank montajı üretim standart zamanının ise 7.26 dakika olduğu tespit edilmiştir. Buna göre, işletmedeki proses etkinliği göz önüne alınarak değerlendirildiğinde işletmede tam üretim kapasitesine ulaşılamadığı belirlenmiştir. Sonuç olarak, zaman etüdü uygulaması ile incelenen işletmenin üretim kapasitesinin çok altında çalıştığ belirlenmiş olup, işletmenin öncelikli olarak esnek üretim sistemlerine göre yeniden planlanmasının sağlanarak üretim miktarını ve verimliliğini arttırabileceği ortaya çıkmıştır. Ayrıca, ahşap kent mobilyası ve benzeri üretim alanları için zaman etüdü uygulamaları ile işletmelerin ileriye dönük yatırım ve maliyet hesaplarına kaynak teşkil edebilecek veri alt yapısına sahip olabileceği belirlenmiştir.

Anahtar kelimeler: Zaman etüdü, Ahşap kent mobilyası, İş etüdü.

\section{Time study and an example of application in wood urban furniture}

\section{Abstract}

In this study, due to the fact that there is no sufficient application in the furniture industry and there are no scientific studies regarding the time study in this industry, a time study application was examined through the example of the production of wooden urban furniture. Within the framework of the research, 10 preliminary studies were conducted. As a result of the preliminary study conducted in this context, at the three machines and one stage, 10 times measurements were made. Standard deviations have been calculated with $95 \%$ confidence and 5\% margin of error. Time study has been applied for the determination of the standard time in the assembly stage of the picnic table and the bench, which are the products of an enterprise producing wooden urban furniture. When the evaluation is made over the basic time data obtained in this context, it has been determined that the standard time for the assembly of one picnic table is 11.58 minutes, and the bench assembly production standard time is 7.26 minutes. Accordingly, considering the process efficiency in the enterprise, it was determined that the full production capacity in the enterprise could not be reached. As a result, it has been determined that the enterprise studied with the time study application is operating well below its production capacity and it has been revealed that the enterprise can increase production quantity and efficiency by ensuring that the enterprise is primarily planned according to flexible production systems. In addition, it has been determined that the enterprises may have data infrastructure that may be a source for future investment and cost calculations by time study applications for wood urban furniture and similar production areas.

Keywords: Time study, Wooden urban furniture, Work study.

Makale tarihçesi: Geliş:21.05.2021, Kabül:17.06.2021, Yayınlanma:28.06.2021. *e-posta: tuncerd@iuc.edu.tr, 'İstanbul Üniversitesi-Cerrahpaşa, Lisansüstü Eğitim Enstitüsü, Orman Endüstri Mühendisliği, İstanbul/Türkiye, ${ }^{2}$ İstanbul Üniversitesi-Cerrahpaşa, Orman Fakültesi, Orman Endüstri Mühendisliği Bölümü, İstanbul/Türkiye, 


\section{Giriş}

Bilindiği gibi günümüz rekabet ortamında işletmelerin var olması, faaliyetlerini sürdürebilmesi ve pazar paylarını arttırabilmeleri öncelikle müşteri memnuniyetinden geçmektedir. Bunun da işletmelerin faaliyetlerine yönelik iş ölçümlerine ve zaman etütlerine sahip olunmasından geçtiğini söyleyebiliriz. Diğer taraftan, yüksek kalite ihtiyac1 ve verimlilik gerçek zamanlı ölçüm sistemlerini gerekli kılmaktadır. (Kurtoğlu ve Dilik, 2018; 2019). Bu çalışmada, zaman etüdü ile ilgili olarak mobilya endüstrisinde yeterli bir uygulamanın olmadığı ve bilimsel çalışmaların bulunmadığı gerçeğinden hareketle, ahşap kent mobilyası üretimi örneği üzerinden bir zaman etüdü uygulaması incelenmiştir.

Zaman etüdü yöntemi, belirli koşullar altında yapılan belli bir işin öğelerinin zamanı ve derecesini kaydederek ve bu yolla toplanan verileri çözümleyerek, o işin tanımlanan bir çalışma hızında (tempoda) yapılabilmesi için gereken zamanı saptamakta kullanılan bir iş ölçme tekniğidir (Kanawaty, 2004, Korkmaz, 2017).

İş etüdü, iş sistemlerinin incelenmesi ve düzenlenmesine ilişkin yöntem ve deneyimlerin, çalışan kişinin iş yapabilme gücünü ve gereksinimlerini de göz önünde tutarak, işin iyileştirilmesi ve işletmenin daha ekonomik çalışmasını sağlamak amacıyla uygulanmasıdır (Bezen, 2007). Zaman etüdü ise, belirli koşullar altında yapılan belirli bir işin öğelerinin zamanını ve derecesini kaydederek ve bu yolla toplanan verileri çözümleyerek, o işin tanımlanan bir çalışma hızında yapılabilmesi için gereken zamanı saptamakta kullanılan bir iş ölçümü tekniğidir. Buradan hareketle, zaman etüdünü, özellikleri belirlenmiş bir işin, kalifiye ve normal tempoda çalışan bir işçi tarafından yapılabilmesi için gerekli olan zamanı tespit etmede kullanılan bir iş ölçümü tekniğidir şeklinde tanımlayabiliriz (Bezen, 2007).

Araştırma kapsamında incelenen ahşap kent mobilyası üretiminde, zaman etüdü uygulaması için kullanılan hammadde ve üretilecek ürünlerin seçiminde, araştırmanın yapıldığı işletmenin üretiminde en çok kullandığ 1 malzeme türleri ve makineler göz önüne alınarak uygulama yapılmıştır. Bu amaçla, zaman etüdü çalışmasında montaj aşamasında ölçümü yapılan ürünlerde kullanılan malzeme seçiminde, literatür araştırmalarında ve sektörde faaliyet gösteren işletmelerde de görüleceği üzere, ahşap kent mobilyası üretiminde Ireko, Sapelli, Tik, Ladin, Lareks ve Sarıçam ağaçlarının masif kerestelerinin kullanılmakta olduğu ve tercih edildiği görülmektedir (Dilik ve Gürsoy, 2017).

$\mathrm{Bu}$ çalışmanın uygulama aşamasında incelenen işletmedeki üretiminde Sarıçam kerestesinin hammadde olarak kullanılmakta olduğu belirlenmiş olup, Sarıçamın (Pinus sylvestris) tercih edilmesinin sebebini, kolay işlenebilir olmasının yanı sıra, fiyatının diğer ağaçlara nazaran uygun olması ve koruyucu yüzey işlemleri ile dış ortama dayanım süresi ile ticari kullanım açısından ön planda tutulması olarak belirtebiliriz (Yücel, 2019; Kurtoğlu ve Dilik,2018).

Çalışmada, incelenen işletmenin özelliği gereği, proje tipi üretim yapan, kent mobilyası ve ahşap yapılar üreten bir işletmenin kent mobilyası olarak ürettiği ürünlerden bank ve piknik masası üretiminin montaj aşamasındaki zaman etüdünün yapılması planlanmıştır. Bu amaçla, işletmeninin kapasitesinin ve standart üretim zamanlarının kayıt altına alınarak belirlenmesi, aynı zamanda sektörel olarak yeni üretim metotlarının ve standart zamanların oluşmasına katkı sağlanması hedeflenmiştir. Ayrıca, etkin olunamayan süreleri tespit ederek,işçilerin fiziksel ve zihinsel yorgunluklarının azaltılıp verimin arttırılması, yatırım maliyeti olmaksızın var olan şartlar ile üretimin arttırılmasını da araştırmanın amaçları olarak siralayabiliriz. 


\section{Materyal ve Metot}

$\mathrm{Bu}$ çalışmada, proje tipi üretim yapan, kent mobilyası ve ahşap yapılar üreten bir işletmenin kent mobilyası olarak ürettiği ürünlerden, piknik masası (Şekil 1) ve bank (Şekil 2) üretiminin montaj aşamasındaki zaman etüdü çalışması yapılmıştır.

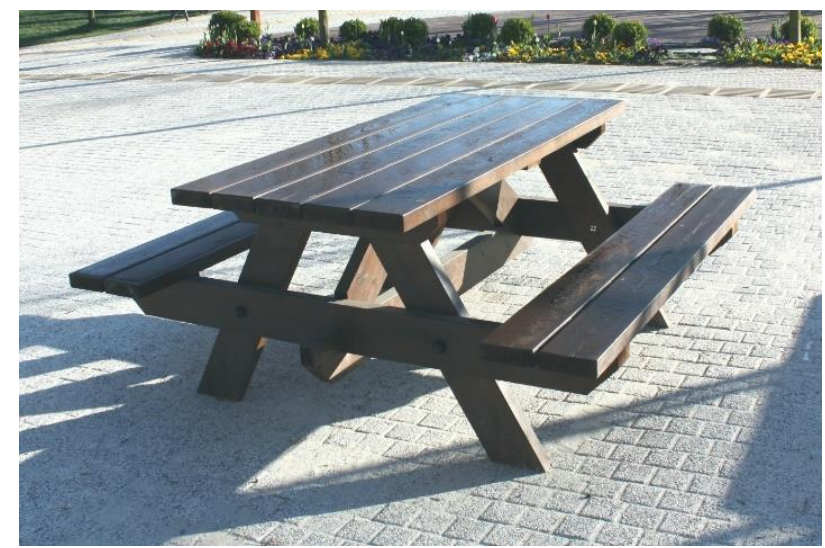

Şekil 1. Piknik masası örneği

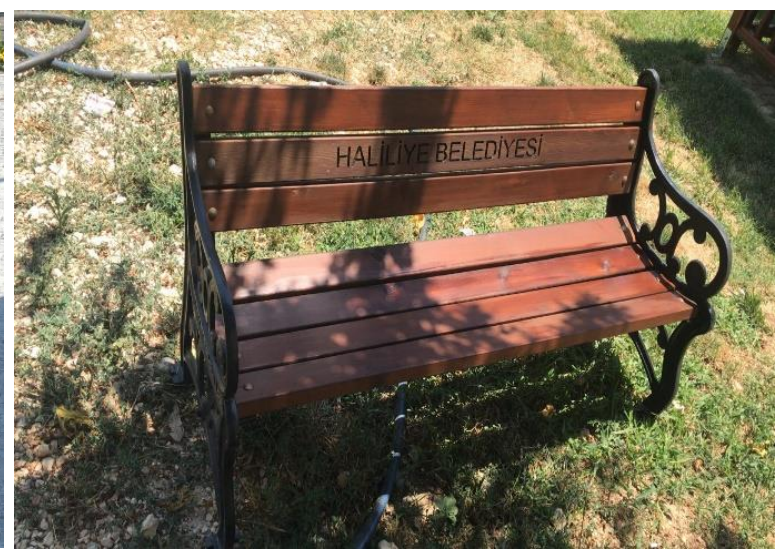

Şekil 2. Bank örneği

Araştırmada uygulanan yöntemin aşamalarını literatür bilgilerine dayanarak aşağıdaki gibi stralayabiliriz (Kanawaty, 2004; Doğruer, 2016; Yücel, 2019):

1) Zaman etüdü yöntemi uygulanacak iş, işçi ve iş istasyonunun seçilmesi.

2) Çevre koşulları hakkında bilginin toplanması (iş, işçi, iş istasyonu ve işin yapılmasını etkileyen etmenler) ve kaydedilmesi.

3) Zaman etüdü yapılacak iş ölçüme uygun şekilde elemanlarına ayrılması.

4) Gözlem ve ölçümlerin yapılması, kaydedilmesi.

5) Gereken gözlem sayısının hesaplanması ( $\mathrm{Bu}$ amaçla aşağıdaki formül (1) kullanılabilir). Gözlem Sayısının Belirlenmesi (Kurt ve Dağdeviren, 2011).

$N^{\prime}=\left[\frac{40 \sqrt{N \Sigma x^{2}-(\Sigma x)^{2}}}{\sum x}\right]^{2}$

Burada; $N^{\prime}$ : yapılması gereken gözlem sayısını (\%95 güven düzeyi ve $\pm \% 5$ hata payı ile) (adet), $N$ : mevcut durumda yapılan gözlem sayısını (adet), $X$ : okunan değerler

6) Çalışma hızının derecelendirilmesi, takdir edilmesi $\mathrm{Bu}$ amaçla, Çizelge 1'den faydalanilır.

Çizelge 1. 0-100 derecelendirme ölçeği (Kanawaty, 2004).

\begin{tabular}{|l|c|}
\hline \multicolumn{1}{|c|}{ TANIM } & ÖLÇEK 0-100 \\
\hline Etkinlik yok & 50 \\
\hline $\begin{array}{l}\text { Çok yavaş; beceriksiz, kararsız, işçi yarı uyur vaziyette, işle ilgili } \\
\text { değil }\end{array}$ & 75 \\
\hline $\begin{array}{l}\text { Dengeli, düşünceli, kaygısız performans, iyi bir denetim altında } \\
\text { çalışan iş̧̧ gibi, zamanı isteyerek israf etmez. }\end{array}$ & 100 (standart hız) \\
\hline $\begin{array}{l}\text { Canlı, düzenli performans, nitelikli işçide olduğu gibi gerekli kalite } \\
\text { standardı ve doğruluk güvenle elde edilebilir }\end{array}$ & 125 \\
\hline $\begin{array}{l}\text { Çok hızlı; işçi eğitilmiş ortalama işçinin çok üstünde bir güven, } \\
\text { beceri ve hareketlerinde uyum gösterir. }\end{array}$ & 150 \\
\hline $\begin{array}{l}\text { Son derece hızlı; çok fazla dikkat ve çaba gerektirir ve uzun zaman } \\
\text { sürdürülmesi olanaksızdır, ancak son derece yetenekli birkaç işçinin } \\
\text { ulaşabileceği üstün düzeyde performanstır. }\end{array}$ & \\
\hline
\end{tabular}


7) Gözlemi yapılan zamanların temel zamanlara dönüştürülüp hesaplanması.

8) Normal zamana ek olarak payların (toleransların) tespiti. Yapılan işe göre Çizelge 2'den faydalanılabilir.

Çizelge 2. Dinlenme payları tablosu (Kobu, 2010).

\begin{tabular}{|c|c|}
\hline \multicolumn{2}{|l|}{ DINNLENME PAYLARI } \\
\hline FAKTÖRLER & PAYLAR (\%) \\
\hline A)KİŞISEL İHTIYAÇLAR & $2-5$ \\
\hline \multicolumn{2}{|l|}{ B) YORULMA PAYLARI } \\
\hline \multicolumn{2}{|l|}{ 1) Bedensel Çaba Yorgunluğu ve Beceri } \\
\hline Çok hafif & 2 \\
\hline Hafif ve ustalik isteyen & 4 \\
\hline Orta ağırlıkta ve ustalık isteyen & 8 \\
\hline A & 16 \\
\hline Çok ağır & 24 \\
\hline \multicolumn{2}{|l|}{ 2)Düşünsel Çaba Yorgunluğu } \\
\hline$\% 30-40$ yoğunluk & 1 \\
\hline$\% 41-50$ yoğunluk & 2 \\
\hline$\% 51-75$ yoğunluk & 4 \\
\hline$\% 76$ ve fazlası yoğunluk & 8 \\
\hline \multicolumn{2}{|l|}{ 3) Çalışma Esnasındaki Duruş Pozisyonu } \\
\hline Oturma & 1 \\
\hline Ayakta & 2 \\
\hline Eğilme ve uzanma & 4 \\
\hline Yürüme & 10 \\
\hline \multicolumn{2}{|l|}{ 4) Gürültüi } \\
\hline Normal sesle konuşmak & 0 \\
\hline Konuşmak için ses yükseltmek gerekirse & 1 \\
\hline Bağırarak konuşulabiliyorsa & 2 \\
\hline Gürültü konuşmayı engelliyorsa & 4 \\
\hline Düzensiz ve sürekli normal gürültü varsa & 1 \\
\hline \multicolumn{2}{|l|}{ 5) Göz Yorgunluğu } \\
\hline Çıplak gözle yapılan işler & 0 \\
\hline Gözlük kullanılıyorsa & 4 \\
\hline Mikroskop ve benzeri cihazlar kullanıliyorsa & 6 \\
\hline \multicolumn{2}{|l|}{ 6) Çevre ve Ortam Şartları } \\
\hline Büro ve benzeri yerler & 0 \\
\hline Duman ve yağ kokusu olan yerler & 3 \\
\hline Aşı1rı rahatsızlık veren unsurlar varsa & 6 \\
\hline Aşı1rı soğuk ve sıcak ortamlarda & 6 \\
\hline Zararlı kimyasal maddelerin bulunduğu yerlerde & 6 \\
\hline \multicolumn{2}{|l|}{ C) GECIKME PAYLARI } \\
\hline Dinlenme araları verilmesi (çay içme ve benzeri gibi) & 0 \\
\hline Arızi & $1-5$ \\
\hline Hazırl1k & 0 \\
\hline
\end{tabular}


9) Zaman etüdü yapılan işlemin standart zamanının hesaplanması aşağıda açıklandığı gibi yapılmaktadır.

Standart zamanın hesaplanmasında aşağıdaki formül ve eşitlikler kullanılır:

Ölçülen Zaman : ÖZ

Normal Zaman : NZ

Standart Zaman : SZ

Tempo : R (\%)

Tolerans $(\%): \alpha$

SZ: $(\mathrm{OZZ} \times \mathrm{R})+(\mathrm{ÖZ} \times \mathrm{R} \times \alpha)$ hesaplanır. NZ=(ÖZ x R) olduğundan,

$\mathrm{SZ}: \mathrm{NZ}+(\mathrm{NZ} \times \boldsymbol{x})$ olacaktır, buradan da $\mathrm{SZ}=\mathrm{NZ}(1+\alpha)$ olur. Fakat bu formülle işlem yapıldığında birim süre zaman parça adedine göre hesaplama yapılması sonucu ortaya çıkan hesap farklılıkları söz konusu olabilmektedir. Bu nedenle, çalışmada en kesin sonucu vermesi sebebiyle aşağıdaki formül (2) kullanılmıştır (Kobu, 2010).

$$
\mathrm{SZ}=\mathrm{NZ} \times \frac{100}{100-\alpha}
$$

Araştırma kapsamında elde edilen bulgular SPSS paket programı yardımıyla Tek Örnek Kolmogorov-Simirnov testi ile değerlendirilerek, normal dağılım gösterip göstermedikleri \%95 güven düzeyinde test edilmiştir.

\section{Bulgular ve Tartışma}

Araştırmada zaman etüdünün aşamalarında belirtildiği, ölçümü yapılacak iş elemanlarına ayrıldıktan sonra derecelendirme ile temel zamanlar belirlenmiş, temel zamanlara paylar eklenerek standart zamanlara ulaşılmıştır. Bu amaçla, öncelikle örnek olarak incelenen ürünlere ait olmak üzere, işlemleri tamamlanan piknik masası ve bank kayıtları paletler halinde montaj bölümüne getirilip, daha önceden hazırlanmış kalıp masaları yardımıyla montaj işlemi başlatılmıştır.

Bank ve piknik masalarının montajı sırasında her iki ürün içinde ikişer adet işçi çalıştırılmıştır.

Montaj için gerekli olan tüm cıvata, pul, somun, rondela, tapa ve vidalar, montaj sırasında kullanılacak olan el aletleri; şarjlı vidalama makinesi, somun sıkma makinesi, plastik tokmaklar, delme burguları, vidalama uçları montaj alanında hazır bir vaziyete getirilmiştir. Her iki ürün içinde dinlenme payları ve toleranslar tespit edilmiştir. Piknik masası ve bank montajı elemanlarının tamamı işçiye bağlı elemanlar olduğu görülmektedir.

Piknik masası montajı daha önceden ustalar tarafından imal edilmiş olan kalıp masasında montajlanmaktadır. Piknik masası montajı için işin elemanlarına ayrılması aşağıda açıklandığı gibi tanımlanmıştır:

1. eleman: Masa bağlantı parçalarına ön delik açılması,

2. eleman: Oturma bağlantı parçalarına ön delik açılması,

3. eleman: Bağlantı cıvata somun ve tapaların hazırlanması,

4. eleman: Masa üst tabla parçalarının kalıp masasına yerleştirilmesi,

5. eleman: Masa üst tablaya masa bağlantı parçaları ve klapanın vidalanması ve masa tablasının kalıptan sökümü, 
6. eleman: Oturma kaplama kayıtlarının kalıba yerleştirilmesi,

7. eleman: Oturma bağlantı parçalarının ve klapanın oturma kaplamalarına vidalanması,

8. eleman: Oturma kaplamaların kalıptan sökümü,

9. elaman: Masa altı karkasların ayaklar ile bağlanması,

10. eleman: Masa tablasının ayak karkas bağlantısına cıvatalar ile bağlanması,

11. eleman: Masa altı çapraz kayıtların vidalanması,

12. eleman: Oturma kaplamaların ayak karkas kısmına vidalanması.

Bank için montajın elemanlarına ayrılması işlemi ise aşağıda açıklandığı gibi tanımlanmıştır:

1. eleman: bank kayıtlarına cıvataların çakılması,

2. eleman: Oturma ve sırtlık kısmına yerleştirilecek kayıtlarının döküm ayaklar üzerine yerleştirilmesi,

3. eleman: Somunların ve pulların gevşek bir şekilde elle cıvatalara sıkıştırılması,

4. eleman: Somunların vidalama makinesi ile sıkıştırılması,

5. elman: Alt orta bağlantı milinin bağlanması.

Bu kapsamda yapılan çalışmalar sonucu, piknik masası ve bank için montaj işlemine ait temel zamanlar ve standart zamanlara ait bulgular Çizelge 3, Çizelge 4 ve Çizelge 5 te gösterildiği gibi belirlenmiştir. Buna göre, piknik masası için montaj aşamasında standart üretim zamanının 695.14 saniye olduğu ortaya çıkarken, bank için bu üretim zamanının 435.82 saniye olduğu ortaya çıkmıştır. Zaman etüdü çalışmalarında elde edilen bu verilerin, işletmeler çalışma ve işgücü planlamasında önemli bir kaynak olduğu söylenebilir. Zira, bunun önemi çeşitli literatür çalışmalarında da ortaya konulmaktadır. Örneğin, Akyüz (2012)'de levha tipi mobilya üretimi yapılan bir işletmede yapmış olduğu çalışmada zaman etüdü sonucunda üretim miktarının \%7,6 oranında arttırıldığını tespit etmiştir. Ancak bu araştırmanın yapıldığı işletmede daha önce benzer bir çalışma yapılmadığı için kapasite artışına yönelik bir karşılaştırma yapılamamıştır. Bundan sonraki benzer çalışmalarda elde edilen sonuçlar temel veri olarak esas alınabileceği söylenebilir.

Çizelge 3. Piknik masası ve bank için dinlenme payları tablosu

\begin{tabular}{|l|c|}
\hline \multicolumn{2}{|c|}{ DINLENME PAYLARI } \\
\hline FAKTÖRLER & PAYLAR (\%) \\
\hline A) KİŞ̇̇SL İHTIYAÇLAR & 2 \\
\hline B) YORULMA PAYLARI & \\
\hline 1) Bedensel Çaba Yorgunluğu ve Beceri & 4 \\
\hline Hafif ve ustalık isteyen & 1 \\
\hline 2)Düşünsel Çaba Yorgunluğu & \\
\hline \%30-40 yoğunluk & 4 \\
\hline 3) Çalışma Esnasındaki Duruş Pozisyonu & 0 \\
\hline Eğilme ve Uzanma & \\
\hline 4) Gürülttü & 0 \\
\hline Normal sesle konuşmak & \\
\hline 5) Göz Yorgunluğu & 3 \\
\hline Çıplak gözle yapılan işler & 14 \\
\hline 6) Çevre ve Ortam Şartları & \\
\hline Duman ve yağ kokusu olan yerler & \\
\hline C) GECİKME PAYLARI & \\
\hline TOPLAM & \\
\hline
\end{tabular}


Çizelge 4. Piknik masası montajı için tespit edilen standart zamanlar tablosu

\begin{tabular}{|c|c|c|c|c|c|c|c|c|c|c|c|c|}
\hline & & & & TAND & ART Z & AMAN & LARIN & TESPİ & & & & \\
\hline İşlem: M & ONTA. & AŞAN & ASI P & KNİK & MASAS & $\mathrm{MON}^{\prime}$ & AJI & & & & & \\
\hline PAY OR & ANI: & & & & & & & & & & & \\
\hline $\begin{array}{l}\text { SZ= } \\
\text { STANDA } \\
\text { ZAMAN }\end{array}$ & RT & $\begin{array}{l}\mathrm{SZ}=\mathrm{T} \\
\mathrm{PAY}\end{array}$ & $\begin{array}{l}x(100 / \\
\text { RANI })\end{array}$ & $100-$ & $\begin{array}{l}\mathrm{TZ}=\mathrm{T} \\
\mathrm{ZAM}\end{array}$ & $\begin{array}{l}\text { EMEL } \\
\mathrm{N}\end{array}$ & & $\overline{\mathrm{x}}=\mathrm{ORT}$ & LAMA & $\begin{array}{l}\mathrm{S}=\mathrm{STA} \\
\mathrm{SAPM}\end{array}$ & ART & \\
\hline ELEMAN & & & & $\mathrm{ST}$ & NDAF & T ZAM & ANLA & & & & $\overline{\mathrm{x}}$ & $\mathrm{S}$ \\
\hline & SZ1 & SZ2 & SZ3 & SZ4 & SZ5 & SZ6 & SZ7 & SZ8 & SZ9 & SZ10 & & \\
\hline 1 & 66.28 & 67.97 & 68.66 & 69.13 & 75.83 & 72.14 & 70.43 & 68.81 & 76.28 & 72.97 & 70.85 & 3.36 \\
\hline 2 & 23.95 & 25.83 & 24.79 & 26.35 & 27.27 & 28.02 & 27.41 & 27.78 & 26.43 & 26.58 & 26.44 & 1.30 \\
\hline 3 & 39.98 & 40.79 & 41.63 & 39.30 & 41.31 & 38.99 & 41.92 & 42.44 & 40.17 & 40.67 & 40.72 & 1.13 \\
\hline 4 & 27.08 & 28.85 & 29.97 & 31.20 & 31.51 & 32.70 & 27.18 & 27.42 & 29.72 & 26.95 & 29.26 & 2.09 \\
\hline 5 & 179.65 & 190.03 & 193.52 & 186.45 & 187.79 & 181.70 & 188.62 & 192.04 & 181.47 & 182.28 & 186.36 & 4.85 \\
\hline 6 & 21.50 & 25.65 & 23.94 & 27.01 & 24.99 & 21.91 & 22.80 & 23.64 & 26.41 & 26.20 & 24.41 & 1.94 \\
\hline 7 & 44.77 & 42.69 & 41.79 & 42.37 & 43.79 & 43.15 & 41.71 & 42.65 & 43.87 & 42.95 & 42.97 & 0.96 \\
\hline 8 & 14.87 & 15.09 & 15.70 & 15.40 & 16.40 & 14.72 & 15.06 & 17.29 & 15.93 & 15.33 & 15.58 & 0.79 \\
\hline 9 & 117.29 & 129.01 & 133.86 & 135.73 & 111.09 & 131.73 & 137.99 & 138.72 & 113.59 & 131.08 & 128.01 & 10.23 \\
\hline 10 & 28.32 & 26.13 & 25.79 & 26.29 & 25.02 & 25.68 & 24.66 & 26.20 & 26.00 & 27.64 & 26.17 & 1.10 \\
\hline 11 & 43.69 & 44.34 & 45.97 & 42.78 & 43.12 & 44.65 & 47.81 & 47.17 & 46.00 & 47.33 & 45.28 & 1.82 \\
\hline 12 & 57.45 & 60.52 & 61.16 & 57.64 & 57.59 & 59.41 & 58.28 & 57.42 & 62.47 & 58.92 & 59.09 & 1.77 \\
\hline TOPLAM & 664.83 & 696.89 & 706.78 & 699.64 & 685.71 & 694.82 & 703.87 & 711.60 & 688.34 & 698.89 & 695.14 & 13.23 \\
\hline
\end{tabular}

Çizelge 5. Bank montajı için tespit edilen standart zamanlar tablosu

\begin{tabular}{|c|c|c|c|c|c|c|c|c|c|c|c|c|}
\hline & & & & ANDA & $\mathrm{RT} \mathrm{ZA}$ & MANL & RIN T & ESPIT & & & & \\
\hline İşlem: M & DNTAJ & AŞAM & ASI BA & NK MO & NTAJI & & & & & & & \\
\hline PAY OR & ANI: 1 & & & & & & & & & & & \\
\hline $\begin{array}{l}\text { SZ= } \\
\text { STANDAl } \\
\text { ZAMAN }\end{array}$ & & $\begin{array}{l}\mathrm{SZ}=\mathrm{TZ} \\
\text { ORAN }\end{array}$ & ) & 0-PAY & $\begin{array}{l}\mathrm{TZ}=\mathrm{TH} \\
\mathrm{ZAMA}\end{array}$ & $\begin{array}{l}\text { MEL } \\
\text { N }\end{array}$ & & $\overline{\mathrm{x}}=\mathrm{ORT}$ & LAMA & $\begin{array}{l}\mathrm{S}=\mathrm{STA} \\
\mathrm{SAPM}\end{array}$ & NDART & \\
\hline ELEMAN & & & & STAI & IDART & ZAMA & NLAR & & & & & \\
\hline & SZ1 & SZ2 & SZ3 & SZ4 & SZ5 & SZ6 & SZ7 & SZ8 & SZ9 & SZ10 & $\mathrm{X}$ & $S$ \\
\hline 1 & 196.40 & 199.31 & 203.19 & 198.28 & 204.74 & 196.56 & 202.88 & 204.00 & 197.51 & 198.20 & 200.11 & 3.24 \\
\hline 2 & 82.27 & 82.43 & 88.77 & 90.87 & 89.77 & 82.20 & 84.90 & 83.69 & 84.17 & 87.27 & 85.63 & 3.28 \\
\hline 3 & 73.82 & 78.71 & 79.68 & 72.90 & 74.24 & 75.48 & 77.15 & 76.03 & 77.56 & 74.67 & 76.02 & 2.21 \\
\hline 4 & 72.40 & 74.58 & 76.07 & 73.80 & 71.93 & 74.72 & 76.33 & 72.75 & 74.39 & 73.60 & 74.06 & 146 \\
\hline 5 & 104.86 & 106.58 & 109.69 & 106.81 & 112.14 & 105.80 & 106.17 & 108.81 & 107.17 & 105.41 & 107.35 & 2.24 \\
\hline TOPLAM & 424.88 & 435.03 & 447.71 & 435.85 & 440.68 & 428.97 & 441.26 & 436.47 & 433.63 & 433.73 & 435.82 & 6.42 \\
\hline
\end{tabular}

\section{SONUÇLAR}

Araştırma kapsamında incelenen işletmedeki piknik masası ve bank üretimindeki montaj aşamasına yönelik zaman etüdüne dayanarak aşağıdaki sonuçlar ileri sürülmüştür.

- Zaman etüdü; işçi ve üretim verimliliği konusunda, kayıp zamanların tespiti konusunda, yönetimden kaynaklı aksamaların tespitinde, işletme adına ve bu sektörde çalışan, çalışmayı düşünenler adına fayda sağlayacak bir çalışmadır.

- Çalışma bulgularında bahsedilen zamanlar göz önüne alındığında; incelenen fabrikanın günde 10 saat çalışmakta olduğu, bu 10 saatin; 1 saatinin yemek molası ve 15 dakikalık 2 defa çay molası düşüldüğünde 510 dakikalık net çalışma süresinin olduğu tespit edilmiştir. Ayrıca, çalışma kapsamında montaj aşamasında günde 44.04 
adet piknik masası montajının tamamlanabildiği, bank olarak ise bir günde 70.24 adet bankın montajlandığı belirlenmiştir. Buradan, araştırmanın yapıldığı işletmenin üretim kayıtları tutması ve istatistiki bir veri kaynağı oluşturması bakımından yetersizlik içinde olduğu ve işletmede öncelikle bu amaçla bir metot geliştirme çalışması yapılması gerekliliği ortaya çıkmıştır.

- İncelenen işletmede montaj aşamasında 2 işçinin çalıştığı gerçeğinden hareketle belirlenen bu tespitlere göre, işçi sayısının arttırılarak montajı yapılan bank ve piknik masası sayısının arttırılabileceği ortaya çıkmıştır.

- Ayrıca, bu çalışmada, zaman etüdü ile ilgili olarak orman endüstrisinde yeteri kadar çalışma olmadığı tespiti ile birlikte bunun gibi çalışmaların özellikle ahşap kent mobilyası üreticileri için kaynak teşkil edebileceği ve orman endüstrisi alanında çalışanlara yararlı olabileceği sonucu ve önerisi ortaya çıkmıştır.

\section{Teşekkür}

$\mathrm{Bu}$ makale, birinci yazarın İstanbul Üniversitesi-Cerrahpaşa Lisansüstü Eğitim Enstitüsünde yapmış olduğu "Ahşap Kent Mobilyası Üretiminde Zaman Etüdü Uygulaması" isimli Yüksek Lisans Tezindeki verilerden yararlanılarak hazırlanmıştır. 02-05 Kasım 2020 tarihinde düzenlenmiş olan "VI. INTERNATIONAL FURNITURE CONGRESS-IFC 2020 KTÜ, TRABZON/TURKEY" Kongrede sözlü olarak sunulmuştur. Araştırmanın uygulama çalışmalarına sağladığı olanak ve katkılarından dolayı "Turkuaz Park Ahşap Yapı Peyzaj İnş. San. Tic. Ltd. Şti. İşletmesine" teşekkürlerimizi sunarız.

\section{Kaynaklar}

Akyüz, I., (2012), Yatak odası mobilyası üretiminde zaman etüdü uygulaması, Karadeniz Teknik Üniversitesi, Fen Bilimleri Enstitüsü, Yüksek Lisans Tezi. Trabzon.

Bezen, A., (2007), İş etüdü teknikleri ile kalite ve müşteri memnuniyeti ilişkisi: Ambalaj sektöründe bir uygulama, Dumlupınar Üniversitesi, Fen Bilimleri Enstitüsü, Yüksek Lisans Tezi.

Dilik, T., Gürsoy, S., (2017), Kent mobilyasında ahşap malzeme kullanımı ve seçimine yönelik güncel bir değerlendirme, Illeri Teknoloji Bilimleri Dergisi, 847-856.

Doğruer, İ. M., (2016), İş Etüdü, Açılım Kitap, İstanbul.

Kanawaty, G., (2004), İş Etüdü, Milli Podüktivite Merkezi Yayınları/ ILO:29, Ankara.

Kobu, B., (2010), Üretim Yönetimi, Beta Basım Yayım Dağıtım A.Ş., İstanbul.

Korkmaz, İ. H., (2017), İşletmelerin lojistik faaliyetlerinde iş analizi ve zaman etüdü: Gaziantep'te Bir Vaka İncelemesi, Gaziantep Üniversitesi, Sosyal Bilimleri Enstitüsü, Doktora Tezi.

Kurt, M., Dağdeviren, M., (2011), İş Etüdü, YESD Yayınevi, Ankara.

Kurtoğlu, A., Dilik, T., (2018), Mobilya ve Doğrama Konstrüksiyonları Ders Notu (Basılmamıştır), İ.Ü.-Cerrahpaşa Orman Fakültesi, Orman Endüstri Mühendisliği Bölümü, Bahçeköy/İstanbul

Kurtoğlu, A., Dilik, T., (2019), Mobilya Endüstrisi Ders Notu (Basılmamıştır), İ.Ü.Cerrahpaşa Orman Fakültesi, Orman Endüstri Mühendisliği Bölümü, Bahçeköy/İstanbul.

Yücel, H. E., (2019). Ahşap kent mobilyası üretiminde zaman etüdü uygulaması, İstanbul Üniversitesi-Cerrahpaşa Lisansüstü Eğitim Enstitüsü, Yüksek Lisans Tezi. İstanbul. 